\title{
KONFLIK ORANGTUA-ANAK DALAM PEMILIHAN PASANGAN PADA KELUARGA DI BANGKA
}

\author{
Sherly Agustina ${ }^{1}$, Yohanes Budiarto ${ }^{2}$, Rahmah Hastuti ${ }^{3}$ \\ ${ }^{1}$ Fakultas Psikologi, Universitas Tarumanagara \\ Email: sherly.tjhin@gmail.com \\ ${ }^{2}$ Fakultas Psikologi, Universitas Tarumanagara \\ Email: yohanesb@fpsi.untar.ac.id \\ ${ }^{3}$ Fakultas Psikologi, Universitas Tarumanagara \\ Email: rahmahh@fpsi.untar.ac.id
}

\begin{abstract}
ABSTRAK
Konflik orangtua dan anak dapat terjadi dalam berbagai hal. Salah satu permasalahan yang menjadi konflik tersebut adalah preferences mate. Konflik yang terjadi biasanya tidak dapat dihindari. Namun, dalam budaya tertentu seperti budaya kolektif, ada kecenderungan konflik tidak terjadi. Pada pemilihan pasangan sendiri terdapat berbagai karakteristik. Dalam hal ini, akan terdapat kecenderungan orangtua dan anak memiliki kesamaan dalam karakteristik yang diinginkan untuk pemilihan pasangan. Namun, orangtua dan anak juga dapat memiliki perbedaan mengenai karakteristik yang diinginkan dalam pemilihan pasangan. Penelitian ini bertujuan untuk mengetahui konflik orangtua dan anak yang terjadi pada keluarga di Bangka. Selain itu, penelitian ini juga ingin mengetahui karakteristik yang paling didambakan maupun yang paling tidak didambakan dalam preferences mate oleh keluarga di Bangka. Data penelitian ini diambil dari 178 partisipan orangtua dan anak yang tinggal di Bangka. Hasil penelitian ini menunjukkan bahwa tidak terdapat konflik antara orangtua dan anak dalam preferences mate. Temuan penelitian ini juga menunjukkan bahwa karakter baik dan pengertian merupakan karakter yang paling didambakan dalam preferences mate oleh partisipan penelitian. Selain itu, untuk karakteristik yang paling tidak didambakan oleh partisipan penelitian ini adalah sarjana.
\end{abstract}

Kata kunci: konflik orangtua-anak, pemilihan pasangan, budaya kolektif

\section{PENDAHULUAN}

Cerita Romeo dan Juliet mengisahkan sepasang kekasih berakhir tragis setelah mendapatkan penentangan yang kuat dari orangtua mereka terhadap hubungan mereka. Cerita fiksi ini menggambarkan fakta nyata tentang hubungan antara orangtua dan anak mengenai pemilihan pasangan tidak selalu harmonis (Apostolou, 2011). Apostolou (2011) juga mengatakan bahwa orangtua dan anak ingin mendapatkan pasangan dengan penilaian yang terbaik, akan tetapi mereka tidak dapat melakukannya dikarenakan mereka dipengaruhi oleh penilaian mereka sendiri. Oleh karena itu, hal ini memungkinkan terjadinya konflik antara orangtua dan anak.

Menurut Buunk, Park, dan Dubbs (2008), pendapat mengenai pasangan yang ideal menurut orangtua seringkali berbeda dengan pendapat dari pihak anak sehingga terjadi konflik. Dalam pemilihan pasangan, Buunk, Park, dan Dubbs (2008) dalam penelitiannya mengusulkan faktor yang menyebabkan terjadinya konflik antara anak dan orangtua adalah anak lebih mementingkan kriteria yang mengacu pada heritable fitness sedangkan orangtua lebih mementingkan kriteria yang mengacu pada parental investment dan kerja sama in-group.

Penelitian Buunk et al. (2009) memberikan temuan yang semakin menunjang adanya pengaruh orangtua dalam pemilihan pasangan. Pada penelitian Buunk et al. (2009), ditemukan bahwa subyek yang berasal dari Asia Timur mengindikasikan pengaruh orangtua yang lebih kuat 
dibandingkan subyek yang berasal dari Eropa. Negara-negara Asia Timur di dalam penelitian Buunk et al. diyakini memiliki kadar budaya kolektif yang lebih kuat dibandingkan dengan negara-negara Eropa. Oleh karena itu, dapat disimpulkan bahwa pada budaya kolektif, orangtua akan memiliki pengaruh yang lebih besar dalam proses pemilihan pasangan.

Hofstede (dikutip dalam Buunk et al., 2009) mengatakan bahwa budaya individualis dicirikan dengan nilai-nilai seperti otonomi, independensi emosional, hak privasi, dan mencari kenikmatan (kesukaan). Sedangkan, budaya kolektif lebih dicirikan dengan adanya solidaritas kelompok, saling memberi, kewajiban serta kepatuhan, dan keputusan kelompok. Selain itu, karakteristik penting yang terdapat pada budaya kolektif ditekankan pada kesetiaan pada keluarga dan pemenuhan harapan keluarga sedangkan pada budaya individualis menekankan pada kesenangan dan pilihan pribadi. Negara dengan budaya kolektif seperti Cina, Jepang, dan India telah lama dikarakterisasikan dengan tingginya tingkat pengaruh orangtua dalam pemilihan pasangan anak mereka (Applbaum; Riley; Xie \& Combs dikutip dalam Buunk et al., 2009).

Indonesia termasuk salah satu negara dengan kebudayaan kolektif yang kuat (Baron \& Byrne, 2003). Menurut Shiraev dan Levy (2012), budaya kolektif di Asia menekankan agar individu menghindari pertengkaran dengan orang lain, sebab pada budaya Asia, perhatian pada kerukunan dan kebahagiaan orang lain kadang dianggap lebih penting daripada kesenangan diri sendiri. Adanya budaya kolektif yang kuat akan membuat individu lebih tidak mengalami konflik dalam melakukan pemilihan pasangannya.

Di Indonesia terdapat berbagai macam etnis yang tinggal di dalamnya. Etnis Cina merupakan salah satu dari sekian banyak golongan etnis yang terdapat di seluruh wilayah Indonesia dan biasa disebut Etnis Tionghoa. Bangka Belitung merupakan salah satu daerah di Indonesia yang memiliki penduduk yang terdiri dari berbagai etnis. Setiap etnis di Bangka, misalnya etnis Tionghoa (Khek) dan Melayu Bangka memiliki ciri khasnya tersendiri. Kedua etnis ini masih memelihara dan memraktekkan tradisi dan kebudayaan mereka. Salah satu kebudayaan dan tradisi yang masih dipelihara oleh kedua etnis ini adalah mengenai pemilihan pasangan dan pernikahan. Pada etnis Melayu Bangka, anak laki-laki yang telah menjadi seorang suami harus tinggal bersama dengan istrinya di rumah orangtua dari pihak istri. Namun, berbeda halnya dengan tradisi dari Khek (Tionghoa) Bangka, anak laki-laki yang baru saja menikah harus tetap tinggal di rumah orangtuanya bersama dengan istrinya. Selain itu, terdapat ritual seserahan serta pesta sebelum pesta pernikahan yang biasanya dilakukan di rumah mempelai perempuan. Terdapat pula pantangan pasangan pengantin baru tidak boleh keluar dari rumah sebelum melewati tiga hari dari hari pernikahannya. Jika ada yang melanggar pantangan ini, orang Khek percaya bahwa pasangan tersebut akan tertimpa kesialan. Setelah melewati tiga hari pertama, maka pasangan pengantin diharuskan untuk mengunjungi rumah pengantin perempuan sebagai sopan santun telah mengambil anak perempuan dari keluarga pihak pengantin perempuan (personal communication, Juli 19, 2013).

Dari hal pemilihan pasangan, terdapat kriteria-kriteria tertentu yang telah dimiliki oleh tiap etnis di Bangka. Etnis Tionghoa misalnya, dalam memilih pasangan seorang anak akan dihimbau untuk tidak memilih pasangan dengan beda usia enam tahun. Hal ini karena etnis Tionghoa Bangka percaya bahwa pasangan yang berbeda usia enam tahun tidak dapat hidup harmonis.

Berdasarkan pemaparan di atas, maka permasalahan yang muncul adalah bagaimana gambaran parent-offspring conflict dalam preferences mate yang ada di Indonesia terutama di daerah 
Bangka. Dari permasalahan tersebut, maka penelitian ini dilakukan untuk mengetahui lebih lanjut mengenai hubungan antara parent-offspring conflict dan preferences mate.

\section{METODE PENELITIAN \\ Partisipan Penelitian}

Jumlah partisipan dalam penelitian ini adalah 178 orang dewasa yang tinggal di Bangka (Toboali dan Pangkalpinang). Partisipan di dalam penelitian ini terbagi menjadi 65 (20.8\% laki-laki, $15.7 \%$ perempuan) orang subyek yang berperan sebagai anak, 57 (32\%) orang subyek yang berperan sebagai ayah, dan $56(31.5 \%)$ orang subyek yang berperan sebagai ibu.

Partisipan penelitian ini terdiri dari etnis Tionghoa (43.8\%) dan Melayu (56.2\%). Partisipan penelitian dibatasi dengan usia untuk partisipan yang berperan sebagai anak adalah 20-30 tahun sedangkan untuk orangtua tidak dibatasi oleh usia.

\section{Instrumen Penelitian}

Instrumen yang dijadikan sebagai acuan dalam penelitian ini adalah Scale For Parent-Offspring Conflict Over Mate Choice (Buunk et al., 2008) dan Preferences Concerning Potential Mates (Chang, Wang, Shackelford, dan Buss, 2011). Kuesioner yang digunakan menggunakan dua skala yang semuanya mengukur mengenai kriteria-kriteria pemilihan pasangan.

Skala pertama yang digunakan adalah Skala Likert. Skala ini digunakan pada kuesioner dengan empat alternatif jawaban: (1) Sangat Tidak Dapat Diterima, (2) Tidak Dapat Diterima, (3) Dapat Diterima, dan (4) Sangat Dapat diterima. Skala Likert ini digunakan pada bagian kuesioner dengan butir-butir yang diadaptasi dari Scale For Parent-Offspring Conflict Over Mate Choice dari Buunk et al. (2008) dengan alpha cronbach 0.899. Skala ini digunakan sebagai modifikasi dari skala Buunk et al. (2008) supaya sesuai dengan kondisi di lapangan.

Skala kedua yang digunakan dalam kuesioner ini adalah melalui pemberian ranking. Pada skala ini, partisipan akan diminta untuk memberikan ranking pada 13 kriteria yang telah disediakan. Kriteria-kriteria yang telah disediakan merupakan adaptasi dari alat ukur penelitian sebelumnya, yaitu Preferences Concerning Potential Mates (Chang et al., 2011). Pada bagian ini, partisipan diminta untuk memberikan ranking dari ranking 1 pada kriteria yang paling diinginkan dalam memilih pasangan sampai dengan ranking 13 untuk kriteria yang paling tidak diinginkan dalam memilih pasangan.

\section{Prosedur Penelitian}

Data diperoleh melalui penyebaran kuesioner di Toboali dan Pangkalpinang. Kuesioner penelitian disebarkan ke partisipan penelitian dan dibawa pulang untuk diisi oleh partisipan. Setelah itu, kuesioner yang telah diisi dikumpulkan lagi oleh peneliti secara langsung.

\section{HASIL PENELITIAN DAN PEMBAHASAN}

Uji perbedaan dalam penelitian ini menggunakan teknik non parametrik dan parametrik. Hal ini terjadi karena terdapat distribusi data skor yang tidak normal dan normal. Teknik uji beda yang digunakan adalah Independent-Sample T Test untuk kriteria heritable fitness $(\mathrm{Z}=1.114, \mathrm{p}=0.1)$ dan Mann-Whitney $U$ untuk kriteria parental investment dan kerja sama in-group $(\mathrm{Z}=1.458, \mathrm{p}=$ $0.029)$, serta kriteria karakteristik tambahan $(\mathrm{Z}=1.728, \mathrm{p}=0.005)$. 
Berdasarkan hasil uji beda dengan menggunakan Independent-Sample T Test, diperoleh nilai t dengan equal variance assumed $=1.48$ dan $p=0.883$. Nilai $p>0.05$, maka tidak terdapat perbedaan skor heritable fitness antara orangtua dan anak. Sedangkan, berdasarkan hasil uji beda dengan menggunakan Mann-Whitney $U$, diperoleh nilai $Z=-0.663$ dan $\mathrm{p}=0.508$ untuk skor parental investment dan kerja sama in-group. Selain itu, diperoleh juga nilai $Z=-2.130$ dan $p=$ 0.033 untuk skor karakteristik tambahan. Hal ini menunjukkan bahwa tidak ada perbedaan skor parental investment dan kerja sama in-group antara orangtua dan anak karena nilai $p>0.05$. Namun, terdapat perbedaan skor karakteristik tambahan antara orangtua dan anak karena nilai $p$ $<0.05$.

Berdasarkan uji deskriptif, diketahui karakteristik yang paling didambakan dalam preferences mate oleh partisipan secara umum berdasarkan nilai modus dan median adalah karakter baik dan pengertian (modus $=1$, median $=2$ ) sedangkan untuk karakteristik yang paling tidak didambakan adalah sarjana (modus $=13$, median $=12$ ). Hasil uji deskriptif pada partisipan anak menyatakan bahwa karakteristik yang paling didambakan dalam preferences mate adalah karakter baik dan pengertian (modus $=1$, median 2 ) sedangkan untuk karakteristik yang paling tidak didambakan adalah sarjana (modus $=13$, median $=12$ ). Selain itu, karakteristik yang paling didambakan dalam preferences mate oleh partisipan orangtua adalah karakter baik dan pengertian (modus = 1, median $=2$ ) sedangkan untuk karakteristik yang paling tidak didambakan adalah sarjana ( modus $=13$, median $=12$ ). Berdasarkan data desktriptif ini, diketahui bahwa tidak ada perbedaan pada karakteristik yang paling didambakan antara orangtua dan anak. Untuk karakteristik yang paling tidak didambakan juga tidak terdapat perbedaan antara orangtua dan anak.

\section{DISKUSI DAN SARAN}

\section{Diskusi}

Hasil penelitian ini menunjukkan bahwa tidak terdapat perbedaan skor parental investment dan kerja sama in-group, serta heritable fitness antara orangtua dan anak. Pada karakteristik tambahan, diketahui terdapat perbedaan individual antara orangtua dan anak. Selain itu, berdasarkan peran partisipan, hasil penelitian menunjukkan bahwa tidak terdapat perbedaan skor heritable fitness maupun parental investment dan kerja sama in-group antara ayah, ibu, anak laki-laki, dan anak perempuan. Hasil penelitian ini tidak mendukung penelitian sebelumnya yang pernah dilakukan oleh Buunk et al. (2008). Menurut penelitian Buunk et al. (2008), konflik orangtua dan anak dalam preferences mate terjadi pada kriteria parental investment dan kerja sama in-group yang terdiri dari (a) latar belakang keluarga yang buruk, (b) latar belakang etnis yang berbeda, (c) latar belakang agama yang berbeda, (d) kelas sosial yang rendah, (e) pernah bercerai, (f) miskin, (g) tidak dapat respek dan patuh, (h) berpendidikan yang rendah, dan (i) tidak menyukai anak-anak, serta kriteria heritable fitness yang terdiri dari (a) tidak menarik secara fisik, (b) lebih pendek atau tinggi, (c) jelek, (d) gemuk, (e) memiliki bau badan, (f) kurang memiliki rasa humor, (g) kurang memiliki kemampuan artistik, (h) kurang kreatif, dan (i) tidak pintar. Hal ini menunjukkan bahwa pada keluarga di Bangka yang terlibat dalam penelitian ini tidak terdapat konflik yang terjadi antara orangtua dan anak mengenai kriteria heritable fitness maupun parental investment serta kerja sama in-group dalam preferences mate. Namun, terdapat konflik yang terjadi antara orangtua dan anak mengenai kriteria karakteristik tambahan (additional characteristics), seperti tidak ramah dan tidak baik, memiliki sikap yang sangat berbeda, memiliki penyakit fisik atau mental, serta status keperawanan atau keperjakaan. Tidak terjadinya konflik orangtua dan anak pada keluarga di Bangka ini dapat disebabkan adanya keinginan dari anak untuk memenuhi harapan keluarga terutama orangtua serta menjaga 
kepatuhan (Hofstede dikutip dalam Buunk et al., 2009). Selain itu, juga dapat disebabkan oleh budaya kolektif yang dimiliki anak sehingga individu menghindari pertengkaran dengan orang lain terutama orangtuanya (Shiraev dan Levy, 2012).

Seluruh partisipan dari penelitian ini berasal dari keluarga Bangka yang memiliki kebudayaan kolektif. Menurut Buunk et al. (2009), pada budaya kolektif, orangtua akan memiliki pengaruh yang lebih besar dalam proses pemilihan pasangan (preferences mate). Hofstede (Buunk et al., 2009) berpendapat bahwa budaya kolektif lebih dicirikan dengan adanya solidaritas kelompok, saling memberi, kewajiban serta kepatuhan, dan keputusan kelompok. Selain itu, karakteristik penting yang sering kali ditekankan dalam budaya kolektif adalah kesetiaan pada keluarga dan pemenuhan harapan keluarga. Oleh karena itu, dapat dikatakan bahwa tidak terjadinya konflik orangtua dan anak pada kriteria yang besar kemungkinan memicu terjadinya konflik dalam pemilihan pasangan dapat disebabkan oleh budaya kolektif yang dimiliki oleh partisipan penelitian ini.

Hasil yang berbeda pada penelitian ini dengan penelitian Buunk et al. (2008) dapat disebabkan adanya perbedaan budaya antara budaya individualis pada partisipan penelitian Buunk et al. di Kanada dan Belanda dengan budaya kolektif yang dimiliki partisipan penelitian ini. Budaya individualis dicirikan dengan nilai-nilai seperti otonomi, independensi emosional, hak privasi, dan mencari kenikmatan. Selain itu, budaya individualis juga menekankan pada kesenangan dan pilihan pribadi. Ciri khas yang dimiliki oleh budaya individualis ini besar kemungkinannya yang menjadi pemicu terjadinya konflik antara orangtua dengan anak dalam pemilihan pasangan pada kriteria-kriteria tertentu.

Berdasarkan suku bangsanya, hasil penelitian menunjukkan adanya perbedaan skor heritable fitness dan karakteristik tambahan antara etnis Tionghoa dan Melayu. Sedangkan, untuk skor parental investment dan kerja sama in-group menunjukkan tidak ada perbedaan antar etnis tersebut. Hal ini dapat dianggap bahwa terdapat perbedaan pada kriteria yang lebih dipilih anak dalam pemilihan pasangannya. Sedangkan, untuk kriteria yang lebih dipilih oleh orangtua tidak terdapat perbedaan antar etnis. Adanya perbedaan dan kesamaan skor yang terjadi menunjukkan bahwa terdapat perbedaan budaya antara etnis Tionghoa dan Melayu dalam melakukan penilaian terhadap karakteristik dalam preferences mate. Namun, terdapat juga kesamaan budaya antara etnis Tionghoa dan Melayu dalam melakukan penilaian terhadap karakteristik dalam preferences mate.

Hasil penelitian ini menunjukkan bahwa karakteristik yang paling didambakan oleh orangtua dan anak adalah baik dan pengertian sedangkan karakteristik yang paling tidak didambakan adalah sarjana. Temuan ini menunjukkan adanya perbedaan dan kesamaan dengan hasil penelitian Perilloux (2011). Perbedaan yang terjadi terdapat pada karakteristik yang paling tidak didambakan. Pada penelitian Perilloux, karakteristik yang paling tidak didambakan adalah pengurus rumah yang baik, sedangkan pada penelitian ini karakteristik yang paling tidak didambakan adalah sarjana. Adapun kesamaan dari hasil penelitian ini dengan penelitian Perilloux adalah pada karakteristik yang paling didambakan dalam preferences mate. Hal yang menjadi persamaan penelitian ini dengan penelitian Perilloux (2011) terkait dengan karakteristik yang paling didambakan orangtua dan anak dalam preferences mate adalah baik dan pengertian.

Hasil temuan dalam penelitian ini yang menunjukkan bahwa karakteristik yang paling tidak didambakan adalah sarjana dapat disebabkan oleh sebagian besar partisipan penelitian ini memiliki latar belakang pendidikan terakhir adalah lulusan SMA. Hal ini sesuai dengan pendapat 
DeGenova (2008) yang menyatakan bahwa ada kecenderungan pada pasangan untuk memilih pasangan yang memiliki latar belakang pendidikan yang sama. Dalam hal ini juga dapat dianggap bahwa kurangnya perhatian partisipan penelitian ini pada faktor pendidikan dapat disebabkan adanya kesamaan pemikiran orangtua dan anak terhadap pendidikan. Oleh karena itu, ada kecenderungan orangtua dan anak kurang memiliki pengetahuan akan pentingnya dan manfaat dari perkembangan pendidikan pada masa yang akan datang.

Pada beberapa penelitian, diketahui bahwa perempuan lebih menginginkan untuk menikah dengan laki-laki yang telah memiliki pekerjaan yang tetap, memiliki pendapatan yang baik, dan berpendidikan tinggi sedangkan laki-laki lebih memerhatikan penampilan fisik dibandingkan karakteristik lainnya (Taylor et al., 2006). Pada penelitian Buss (1986), laki-laki cenderung lebih mendambakan kriteria menarik secara fisik sedangkan pada perempuan, kriteria memiliki penghasilan yang baik dan sarjana merupakan kriteria yang lebih didambakan dibandingkan kriteria lainnya. Hal ini tidak didukung oleh temuan penelitian ini yang menunjukkan pada partisipan anak laki-laki maupun perempuan memilih karakter baik dan pengertian sebagai karakteristik yang paling didambakan. Sedangkan, untuk karakteristik yang paling tidak didambakan adalah sarjana.

\section{Saran}

Saran yang dapat diberikan untuk penelitian selanjutnya adalah penambahan jumlah partisipan penelitian agar diperoleh gambaran parent-offspring conflict pada preferences mates yang lebih signifikan. Tambahan pula, disarankan juga supaya penelitian berikutnya dilakukan dengan setting yang berbeda. Hal ini dimaksudkan agar dapat diketahui kesesuaian alat ukur dengan budaya di Indonesia. Selain itu, dengan adanya setting yang berbeda dapat memberikan gambaran parent-offspring conflict pada preferences mate di Indonesia.

\section{Ucapan Terima Kasih (Acknowledgement)}

Terima kasih kepada para partisipan yang telah berpartisipasi dalam penelitian ini. Terima kasih kepada pihak- pihak yang telah berpartisipasi. Peneliti juga mengucapkan terima kasih kepada pihak Universitas yang telah mendukung dalam penelitian ini.

\section{Daftar Pustaka}

Apostolou, M. (2011). Parent-offspring conflict over mating: A replication and extension study. Journal of Integrated Social Sciences, 2(1), 13-26.

Bank Indonesia Palembang (2006). Laporan perkembangan ekonomi dan perbankan kepulauan Bangka Belitung triwulan I. Palembang.

Baron, R. A. \& Byrne, D. (2003). Social psychology (10 ${ }^{\text {th }}$ ed.). Boston, MA: Allyn \& Bacon.

Buunk, A. P., Park, J. H., \& Dubbs, S. L. (2008). Parent-offspring conflict in mate preferences. Review of General Psychology, 12(1), 47-62.

Buunk, A. P., Park, J. H, \& Duncan, L. A. (2009). Cultural variation in on parental influence on mate choice. Cross-Cultural Research, 20(10), 1-18.

Buss, D. M. \& Barnes, M. (1986). Preferences in human mate selection. Journal of Personality and Social Psychology, 50(3), 559-570.

Buss, D. M., Shackelford, T. K., Kirkpatrick, L. A., \& Larsen, R. J. (2001). A half century of mate preferences: The cultural evolution of values. Journal of Marriage and Family, 63, 491-503.

Chang, L., Wang, Y., Shackelford, T. K., \& Buss, D. M. (2011). Chinese mate preferences: Cultural evolution and continuity across a quarter of a century. Personality and Individual Differences, 50, 678-683.

DeGenova, M. K. (2008). Intimate relationships, marriages, and families ( th $^{\text {th }}$ ed.). Boston, MA: McGraw-Hill. 
Hsiang, M. K. (2009). China-regulations of family relationships, tradition-persistence, and transition. Available FTP: http://family.jrank.org/pages/255/China.html -retrieved July 10, 2012

Hynie, M., Lalonde, R. N, \& Lee, N. (2006). Parent-child value transmission among Chinese immigrants to North America: The case of traditional mate preferences. Cultural Diversity and Ethnic Minority Psychology, 12(2), 230-244.

Hofstede, G. \& Hofstede, G. J. (2005). Cultures and organizationz: Software of the mind (2 ${ }^{\text {nd }}$ ed.). New York, NY: McGraw-Hill.

Kamus Besar Bahasa Indonesia Pusat Bahasa. (2008). Jakarta: Gramedia Pustaka Utama.

Kepulauan Bangka Belitung. (2012). Diunduh dari http://www.kemendagri.go.id/pages/profildaerah/provinsi/detail/19/kepulauan-bangka-belitung

King, L. (2008). The science of psychology. New York, NY: McGraw-Hill.

Koentjaraningrat. (1999). Manusia dan kebudayaan di Indonesia (Cetakan ke-18). Jakarta: Djambatan.

Lestari, S. (2012). Psikologi keluarga: Penanaman nilai dan penanganan konflik dalam keluarga. Jakarta: Kencana Prenada Media Group.

Lykken, D. T. \& Tellegen, A. (1998). Is human mating adventitious or the result of lawful choice? A twin study of mate selection. Available FTP: http:www.cogprints.org/773/0/155.pdf -retrieved July 10, 2012

Myers, D. G. (2010). Social psychology (10 ${ }^{\text {th }}$ ed.). New York, NY: McGraw-Hill.

Oxford. (2008). New York, NY: Oxford University Press.

Papalia, D. E., \& Duskin-Feldman, R. (2012). Experience human development (12 ${ }^{\text {th }}$ ed.). Boston, MA: McGraw-Hill.

Perilloux, C., Fleischman, D., \& Buss, D. M. (2011). Meet the parents: Parent-offspring convergence and divergence in mate preferences. Personality and Individual Differences, 50, 253-358.

Santrock, J. W. (2009). Life span development (12 $2^{\text {th }}$ ed.). New York, NY: McGraw-Hill International.

Shiraev, E. B. \& Levy, D. A. (2012). Psikologi lintas kultural: Pemikiran kritis dan terapan modern (edisi ke-4). Jakarta: Kencana.

Siburian, R. (2010). Etnis Cina di Indonesia fakta komunikasi antar budaya. Pusat Penelitian Kemasyarakatan dan Kebudayaan Lembaga Ilmu Pengetahuan Indonesia. Unpublished manuscript.

Taylor, S. E., Peplau, L. A., \& Sears, D. O. (2006). Social psychology $\left(12^{\text {th }}\right.$ Ed.). New York, NY: Pearson Education International.

Tionghoa-Indonesia. (2007). Diunduh dari http://pantangpulangsebelumpadam.blogspot.com 